\title{
Kombucha Culture and Component Analysis
}

\author{
Wang fei \\ Nanyang Medical College, Nan Yang, He Nan ,China
}

Keywords: Kombucha, bacterial analysis, Kombucha culture, health Mechanism.

\begin{abstract}
A traditional tea drink acidic Fermentation broth contains a variety of nutritional factors, including tea some nutrients, live microbial cells and their metabolites. Kombucha bacteria containing mainly acetic acid bacteria, yeast, lactic acid bacteria and other cells. This paper trained to do Kombucha tea component analysis, and in the course of training in the analysis of $\mathrm{pH}$ and cell concentration Kombucha tea with time changes in their variation. Due to the presence of lactic acid bacteria, $\mathrm{pH}$ has declined after the first rise, after the last increase in the value of certain stabilized. During the culture, the concentration of the bacteria that is the number of yeast and acetic acid bacteria belonging to the overall rise, especially in the first nine days maximum, then cultured for several days as to increase their growth rate slowed down. Their health for the latter study provides a theoretical mechanism basis.
\end{abstract}

\section{Foreword}

Kombucha is a popular folk an acidic drink that is sugar for the tea fermentation substrate, the acetic acid bacteria, yeast and lactic acid bacteria and other microorganisms common fermented. In our country there are at least several hundred years of drinking history. Kombucha later spread to other countries, in Japan and Europe and also the rise of the corresponding application and research ${ }^{[1]}$. Although China for drinking Kombucha relatively long history, but its mechanism of scientific research related to the fermentation has started late. 1951 published a famous microbiologist Fang Xinfang "Haibao is what" a text, which is China's first article on the theoretical aspects of the research Kombucha article ${ }^{[2]}$. The 1980's Kombucha drink is very popular in our country, some of the effects and production methods introduced kombucha articles in large numbers.

Kombucha contains a variety of probiotics, which are rich in probiotics gluconic acid, acetic acid, glucose, fructose, proteins, amino acids, vitamins, trace elements, polyphenols, caffeine, alcohol and carbon dioxide ${ }^{[3]}$. So often in our Kombucha as a functional health drink to drink, its health effects as long as reflected in the clean intestines, help digestion, constipation and hemorrhoids have a good preventive effect. Also in the treatment of hypertension, high cholesterol, arteriosclerosis and other cardiovascular and cerebrovascular diseases played a good role. Also it found that long-term drinking kombucha drinks can help people eliminate toxins within the body prevent cancer, enhance the ability of individual immunity ${ }^{[4]}$. In recent years China has made some researchers Kombucha research, but its basic research is not deep enough, especially for hybrid and mixed bacteria Kombucha interaction between species has not conducted systematic research. 


\section{Bacterial microbial composition}

The study found that Kombucha tea contains a variety of beneficial to humans probiotics, these probiotics are mainly acetic acid bacteria, yeast, lactic acid bacteria ${ }^{[5]}$. So far people through a lot of tests Separation finally get major acetic acid bacteria xylinum microorganisms, lactic acid bacteria Lactobacillus bulgaricus. Its species composition shown in Table 1:

Table 1. Acetic acid bacteria and yeasts isolated from kombucha.

\begin{tabular}{|c|c|}
\hline Acetic acid bacteria & Yeast \\
\hline Acetobacter xylinum & Saccharomyces cerevisiae \\
\hline Acetobacter xylinoides & Saccharomyces inconspicus \\
\hline Bacterium gluconicum & Saccharomycodes ludwigii \\
\hline Acetobacter ketogenum & Schizosaccharomyces pombe \\
\hline Acetobacter suboxydans & Candida tropicalis \\
\hline Gluconobacter liquefaciens & Candida krusei \\
\hline Acetobacter aceti & Debaryomyces hansenii \\
\hline Acetobacter pasteurianus & Brettanomyces \\
\hline & Kloeckera \\
\hline & Zygosaccharomyces bailii \\
\hline
\end{tabular}

As can be seen from the table, these bacteria are usually one or more of acetic acid bacteria and yeast composition of one or more, and some have lactic acid bacteria ${ }^{[6]}$. Different species composition, type and quantity of bacteria in its metabolites will be different. Because of its species diversity, Kombucha is complex metabolic processes ${ }^{[7]}$. Acetic acid bacteria and yeasts in the Kombucha is a symbiotic relationship, and plays an important role in the early stages of the fermentation of yeast reproduction.

Training Mature Kombucha tea is clear and transparent, body color is exhibited an orange, light brown at the bottom of a small amount of precipitation. Bacteria floating in the upper layer of membrane synthesis by the acetic acid bacterium gray tough bacterial cellulose membrane, the membrane under flocculent white silk hanging. Its shape shown in Figure 1.

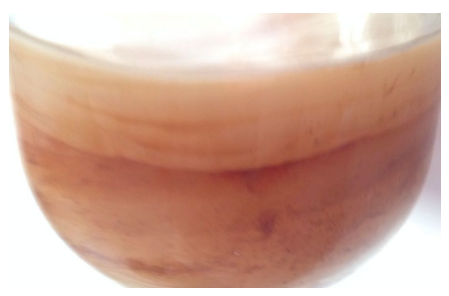

Figure 1. Mature Kombucha tea culture

The study found that the surface layer of medium white film, the main component of $\left(\mathrm{C}_{6} \mathrm{H}_{10} \mathrm{O}_{5}\right)_{n}$, which is composed of a polymer chain wood vinegar bacteria through the $\mathrm{D}$ - glucose to $\beta-1,4$ glycosidic linkages made this polymer material in the form of pure cellulose exists ${ }^{[8]}$. Compared with the bacterial cellulose plant cellulose such novel microorganism formed not only has good water absorption and mechanical properties, and itself has a high crystallinity and high purity characteristics, has demonstrated great commercial value in many areas ${ }^{[9]}$. According to its characteristics such as good water absorption, viscosity and stability in the food and biological fields used for thickening, colloidal filler. At the same time according to its health care features, often used for beverage or related functional food products. 


\section{Training Methods}

The main experimental material used in this experiment with an electric incubator, electric oven, clean workstations, electronic analytical balance, autoclaves, photometer, or acidity, etc.

Premium raw materials are commercially available black tea, high-quality sucrose, $\mathrm{KH}_{2} \mathrm{PO}_{4},\left(\mathrm{NH}_{4}\right)$ ${ }_{2} \mathrm{SO}_{4}$.

Preparation Kombucha media: $5 \mathrm{~g} / 100 \mathrm{~mL}$ sucrose, $0.3 \mathrm{~g} / 100 \mathrm{~mL}$ black tea, $0.1 \mathrm{~g} / 100 \mathrm{~mL} \mathrm{KH}_{2} \mathrm{PO}_{4}$,

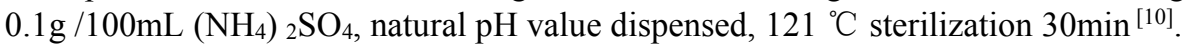

The process shown in Figure 2:

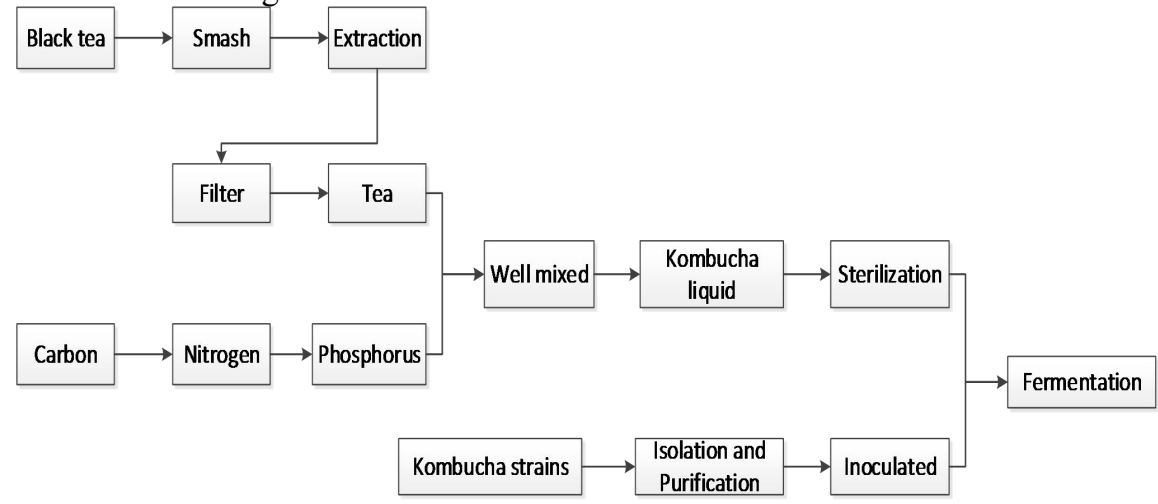

Figure 2. Kombucha culture process

\section{Component Analysis}

Experimental study found that at a temperature of $30{ }^{\circ} \mathrm{C}, \mathrm{pH}$ in the range of 5.5 , the best fermentation product, the highest content of active ingredients, trained Kombucha tea senses of the best ${ }^{[11]}$. Thus, the fermentation broth was cultured for 14 days at $30^{\circ} \mathrm{C}$ incubator, the recording cell concentration and $\mathrm{pH}$ of the case as shown in Fig3.

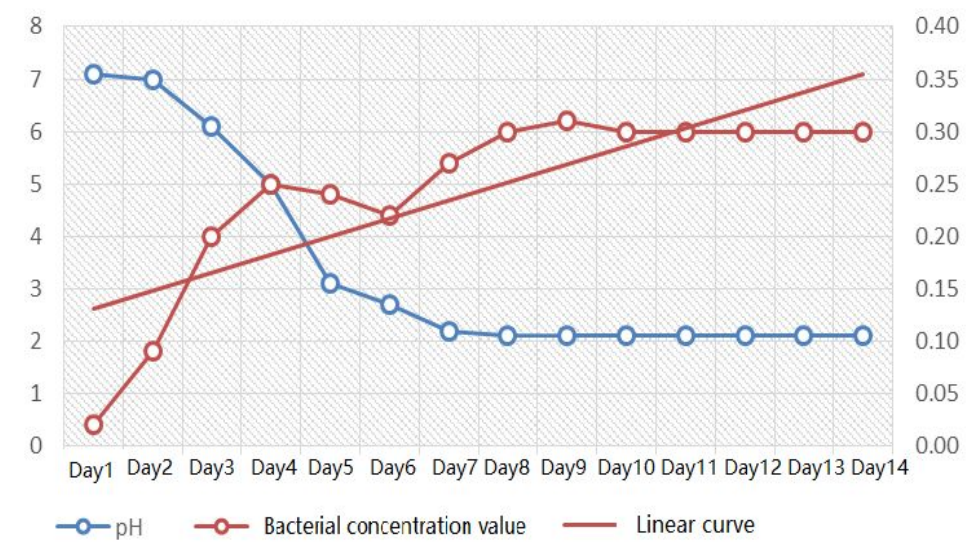

Figure 3. $\mathrm{pH}$ and cell concentrations

We clearly seen from the line graph in the training process in 14 days Kombucha bacteria cells (acetic acid bacteria, yeast, lactic acid) concentrations, there were two inflection value, that on the fourth day and the sixth day. In our analysis, in the fourth day of acetic acid bacteria in the fermentation process produces a large amount of acid, the $\mathrm{pH}$ of the fermentation broth decreased from 7.0 to 4.9 , less than the growth of yeast optimum $\mathrm{pH} 5.5$, the $\mathrm{pH}$ value is not conducive to bacterial growth, so that its concentration. In addition, the plaque bacteria produce acetic acid during 
the fermentation process hindered the transfer of oxygen, lack of oxygen will make the cell concentration is reduced. On the sixth day, the concentration of bacteria appeared to rise, possibly due to the acidic and hypoxic environment conducive to anaerobic - lactic acid bacteria growth, so that the concentration of the bacteria appeared to rise overall, and because the large population of lactic acid bacteria, organic acid-producing further increased, so that the $\mathrm{pH}$ of the broth continues to decrease. However, lower $\mathrm{pH}$ is not conducive to the growth of lactic acid, $\mathrm{pH}$ and the concentration of bacteria so then basically in a stable value.

During the culture, the concentration of the bacteria that is the number of yeast and acetic acid bacteria belonging to the overall rise, especially in the first nine days maximum, then cultured for several days as to increase their growth rate slowed down.

\section{Conclusion and Outlook}

In summary, Kombucha has a long history of folk tradition of acidic beverages, with a variety of health effects, is a very valuable use of natural microbial fermentation products. However, a series of mixed bacteria Isolation Kombucha, mechanism functional ingredients, the active study drug bacteria polysaccharides Kombucha antibacterial protein molecular weight determination and so far has not completely clear, which requires in-depth study.

\section{References}

1. Malhasa R,Loncar E,Djuric M,et a1.Elfect of sucrose concentration on the products of Kombuc; fermentation on molasses [J]. Food Chemistry, 2008, 108:926-932.

2. BAUER-PETROVSKA B, PETRUSHEVSKA-TOZI L. Mineral and water soluble vitamin content in the Kombucha drink [J]. International of Food Science and Technology, 2010, 35(2): 201-205.

3. Chengjiang Feng. Isolation and Determination of Polysaccharide Content kombucha [J] .Northwest Pharmaceutical Journal, 2004, 19 (2): 61-62

4. Xie Junjie, Zhong Qingping, She Shi Wang, research Kombucha liquid antibacterial effect [J] .Food Science and Technology, 2000 (6): 59-60.

5. Jiang Liwen.Isolation, identification and antimicrobial mechanism of Kombucha advantage microorganisms [D]. Changsha: Hunan Agricultural University, 2007

6. Malbasa R, Loncar E, Djuric M.Comparison of the productsof Kombucha fermentation on sucrose and molasses [J]. Food Chemistry, 2013, 106: 1039-1045.

7. S .Study on anti-microbial activities of yeasts isolated from kombucha tea [J]. Gida. 2013, 28(1): 105-108.

8. Ai Leng Teoh, Gillian Heard and Julia Cox.Yeast ecology of fermentation[J]. International Journal of food Microbiology Kombucha. 2004 95(2):119-126.

9. Cletus P. Kurtzman,Christie J.Robnett and Eleanor Basehoar-Powers.Zygosaccharo myces kombuchaensis, a new ascosporogenous yeast from kombucha tea [J]. FEWS Yeast Research, 2001, 1(2): 133-138.

10. BAUER-PETROVSKA B, PETRUSHEVSKA-TOZI L. Mineral and water soluble vitamin content in the Kombucha drink [J]. International of Food Science and Technology, 2010, 35(2): 201-205.

11. Martin Sievers .Microbiology and Fermentation Balance in a kombucha Beverage Obtained from a Tea Fungus Fermentation [J]. Systematic -and-Applied-Microbiology 18(4): 590-594. 